\title{
Assessing the Influence of Responsive Disorder on the Academic Performance of Married Post-graduate Students in North eastern Universities in Nigeria
}

\author{
${ }^{1}$ Amuche Christian Igomu (PhD), ${ }^{2}$ Adamu Naomi Nuhu (PhD) \\ ${ }^{1}$ Department of Educational Foundations, Faculty of Education, Taraba State University, Jalingo, \\ PMB 1167, Jalingo Taraba State Nigeria \\ ${ }^{2}$ Department of Guidance and Counselling, Faculty of Education, Taraba State University, Jalingo, \\ PMB 1167, Jalingo Taraba State Nigeria
}

\begin{abstract}
The study assessed the influence of Responsive disorder on the academic performance of married postgraduate students in North Eastern Universities in Nigeria. Two research questions and two null hypotheses were formulated in harmony with the objectives of the study. The design of this study is survey. The population of the study consist of 22,772 married post-graduate students from 4 Universities in North-east, Nigeria. The sample size for the study was 422 determined using the Proportionate sampling strategy employed at different levels in selection of postgraduate students from the four Universities and along gender lines. The researcher developed two instruments for data collection for the study titled: Students' Responsive disorder Inventory and Research and Statistics Achievement Test. The reliabilities of the instruments yielded 0.84 and 0.87 reliability coefficients of internal consistency for SRDI and RSAT respectively. Descriptive statistics were used to summarize data related to the research questions. Linear regression statistic was used to test the formulated null hypotheses. It was found that postgraduate students face Responsive disorder even with an above average level academic performance. Responsive disorder significantly influenced academic achievement of postgraduate students who are married in Universities in North-east Nigeria. Also, Responsive disorder significantly predicts academic achievement of postgraduate students irrespective of gender. The study concludes that there is relatively high level agreement among postgraduate students in the North-east states with respect to the Responsive disorder faced by them. The finding debunks traditional beliefs that married people are more likely to perform poorly or even drop-out. This study found support for the position that married people may beat the single and even complete their studies before the singles. The study recommends among others that; coping strategies be evolved to help resolve the debacle; Scholarships should be awarded to students to reduce the financial burden, and, efforts should be invested in promoting emotional health among post-graduate students in order to mellow the negative effect on their academic performance.
\end{abstract}

Keywords: Emotion, Disturbance, Academic Performance, Marriage

\section{Introduction}

Responsive disorder is a disorder of the mind marked by symptoms of unhappiness as expressed in feelings of distress, anxiety, anger and frustration, feeling of helplessness and depression with strong unreasonable fears and ideas about the outside world; having troubled relationship with other people, often with feelings of obsession disorders and various other personal and interpersonal imbalances that may even cause physical illness. However, the converse of Responsive disorder is hard to define because it involves a value judgement. But individuals often respond to behaviour primarily in terms of the irritation it produces. The emotional problem may be primary or secondary reactions to other processes of psychological conflicts 
which are contributed by various forms of social pathology, such as economical, educational, marital, vocational failure, delinquency, crime, prostitution alcoholism and drug addiction.

Accordingly, the emotionally disturbed individual is one who has the unusual and persistent difficulty in developing satisfactory and satisfying relationships with people and authorities and in coping with reasonable social demands. The individual may distort the nature of the external world and these distortions may be accompanied by excessive anxiety or guilt which the individual may not consciously recognize. He or she may often have low-self-esteem, a feeling of personal failure and depression. Frequently, the individual's learning in school is affected.

Nevertheless, literature indicates that the influence of emotion on intellectual process has not been given explicit attention until recently. However, recent studies have shown that intellectual process and emotions are intricately intertwined but neither process causes the other (Golombok \& Fivush, 2004). Intellectual functioning according to them is a matter of mental structure while emotion energizes behaviour. Emotions disturbance can speed or slow down intellectual process and influence an individual's operations. Intellectual functioning is linked to emotion through perception, learning and memory but both, according to him are part of an interactive matrix.

Undoubtedly, feelings influence the processing stimulus events. These feelings may facilitate or interfere with learning. They may enhance attention to stimuli or they may bias perception and distort interpretation of events. For instance, when an individual is happy, he is likely to be aware of different aspects of a situation and interpret it differently from when is angry. In this regard, personal problems are either solved for the benefit of the person or remain unsolved to his detriment. Also, unsolved personal disturbances of married students who are purportedly assumed to have family responsibilities have been acknowledged as involved in learning difficulties, and that unsolved personal problems frustrate the learning process and diminish the effects of motivation to learn. This is an indication that when problem persist learning disruptions persist (Walker, 2005).

When students with behaviour problems formally enter the special education system, they generally are labelled with one of several specific terms. Walker (2005) refers to them as "students with emotional disturbance." This label entitles students to special education services. Responsive disorder is a condition exhibiting one or more of the following characteristics over a long period of time and to a marked degree, which adversely affects educational performance:

1. An inability to learn which cannot be explained by intellectual, sensory, or health factors;

2. An inability to build or maintain satisfactory interpersonal relationships with peers and teachers;

3. Inappropriate types of behaviour or feelings under normal circumstances;

4. A general pervasive mood of unhappiness or depression; or

5. A tendency to develop physical symptoms or fears associated with personal or school problems.

Behaviour is the primary area in which students with Responsive disorder are said to differ from others. The behavioural characteristics of Responsive disorder include an inability to learn, an inability to build or maintain satisfactory interpersonal relationships, inappropriate types of behaviour or feelings, pervasive mood of unhappiness or depression, and a tendency to develop physical symptoms or fears. Many inappropriate types of behaviour or feelings are said to be characteristic of emotional disturbance.

Generally speaking, emotional problems can lead to academic problems, and academic problems can lead to emotional problems. When students are suffering emotionally, they can become very preoccupied and simply do not attend well to academics. The academic functioning of students with Responsive disorder is not surprising given that academic underachievement is part of the identifying criteria for emotional disturbance. Although the comorbid existence of Responsive disorder and academic deficits has been documented over time, in recent years, researchers have attempted to elucidate the specific characteristics of the academic performance of students with emotional disturbance.

Multiple studies suggested that married post graduate students with Responsive disorder perform below expectations, with significant differences in achievement as compared to married post graduate students 
without Responsive disorder (Canino, 2001). In a meta-analysis of the academic status of students with emotional disturbance, Somer and Gizzi (2001) reported a general academic functioning level at the 25th percentile with an overall effective size of -.69 , indicating moderate to large differences in achievement as compared to married post graduate students without emotional disturbance. It is therefore, against this background that this study seeks to assess the influence of Responsive disorder on the perceived academic performance of married post-graduate students in North East Universities in Nigeria.

\section{Statement of the Problem}

Students with Responsive disorder are most likely to exhibit broad deficits in academic pursuit as shown through a number of available research works. This is because; a student with Responsive disorder could find it difficult to have focus on academic endeavours. Such students will frequently be distracted, which may affect his or her academic work. A number of hypothetical reasons might explain the phenomenon. The information available to the researcher shows that male and female students with Responsive disorder may have comparable academic achievement deficit. For students to attain high academic performance in any given task, it is of utmost importance for them to have a stable mind which undoubtedly will help enhance their psychological wellbeing. A student with Responsive disorder will find it difficult to have focus on academic endeavours. He or she will frequently be distracted, which may affect his or her academic work. A once intelligent student may find himself or herself performing below average, without knowing the specific factors responsible for poor performance. Interactions with some postgraduate students, who happened to be the researcher's classmates, claimed that they were better off academically when they were undergraduates as compared to the present moment of being postgraduate students. One wonders what could be the reason for this; could it be as a result of their dual roles of taking care of the home and attending to the demands academic work, or could it be as a result of their general state of the minds to excel in their academic work irrespective of other demands? These questions call for answers. The researcher therefore intends to find answers to these questions by carrying out a study that will help postgraduate students with Responsive disorder in their academic performance. Therefore, the thrust of this study was to assess the influence of Responsive disorder on the academic performance of married post-graduate students in Universities in North Eastern geo-political zone of Nigeria.

\section{Purpose of the Study}

The study assessed the influence of Responsive disorder on the academic performance of married postgraduate students in Universities in North Eastern States of Nigeria. Specifically, the study:

1. Examined the Responsive disorder condition of postgraduate students in North-east Nigeria.

2. Ascertained the academic achievement of postgraduate students in North-east Nigerian universities.

3. Examined the influence of Responsive disorder on the academic performance of married postgraduate students in North Eastern universities of Nigeria.

4. Determined the influence of Responsive disorder on the academic performance of married postgraduate male students in North Eastern universities of Nigeria.

5. Assessed the influence of Responsive disorder on the academic performance of married postgraduate female students in North Eastern universities of Nigeria.

\section{Statement of Hypotheses}

The following null hypotheses are postulated and will be tested at 0.05 level of significance:

1. There is no significant relationship between Responsive disorder and the academic performance of married post-graduate students in Universities in North East Nigeria.

2. There is no significant difference in the influence of Responsive disorder on academic performance of married post-graduate students irrespective of gender.

\section{Theoretical Framework}

The theory of Boredom in Achievement setting is used to situate this study. The theory was presented by Reinhard Pekrum of University of Munich, Thomas Goetz of University of Konstanz and Thurque, University of Teachers Education of Alberta, Robert H. Stupnisky of Laval University and lastly, Raymond 
P. Perry of University of Manitoba. In their theory of "Boredom in Achievement they presented and analysed their view in sub-headings such as;

i. Boredom as an Emotion.

ii. Boredom as an Achievement Emotion.

iii. Boredom versus Lack of Interest and Positive Education.

In a research on boredom in achievement settings, focused on interest and intrinsic motivation by Elliot and Dweck, (2005), the following were the outcomes:

i. Ability and perceived control as antecedents of Boredom.

ii. Lack of stimulation and values as antecedents of Boredom.

iii. Effects of Boredom on Achievement Behaviour.

iv. Effects of Boredom on performance.

Achievement emotions are defined as emotions tied to achievement activities or achievement outcomes (Pekrum, 2006). As a matter of reality; past researchers focus on emotion, induced by achievement outcome, such as fear of failure or pride and shame following the performance feedback. The definition adopted are posits that emotion arising from achievement related activities such as enjoyment and Boredom induced by learning activities are also considered achievement emotions.

Two types of Achievement emotions deferring in object focus can thus be distinguished. Achievement emotion pertaining to on-going achievement related activities and outcome emotion pertaining to the outcomes of these activities (Pekrun et al 2002).Along with object focus, valence (positive vs. negative, pleasant vs. unpleasant) and activation (activating vs. deactivating) are two critical dimensions for describing achievement emotions (Pekrun, 2006). Within these dimensions, Boredom is categorized as a negative, deactivating emotion because it is experienced as unpleasant and involves a reduction of physiological activation. Controversy exists as to whether Boredom can coincide with increase, rather than reduced activation of peripheral physiological process. A lot of students have reported decreased activation as indicated by measure of heart rate, or skin conductance (Fisher, 1993). Some authors have postulated an increase in such activation (Berlyne et al 1960).

However, the available evidence suggests that Boredom first and foremost reduces activation even if an increase of activations follows latter. Increase activation accompanying prolonged Boredom and repetitive activities may result from the investment of mental effort to sustain attention or from anger aroused by situational constraints that prevent escape (London, Schubert \& Washburn, 1998).

The findings of few interviews and surveys suggest that Boredom relates negatively to attention and effort at achievement activities. Using interview with six-and seventh-grade students, Javis and Serfert (2002) found that students withdraw effort at school as a result of experiencing Boredom. Farmer and Surdberg (1986) reported that undergraduates, Boredom proneness correlated negatively with their attentiveness during lectures. In Watt \&Vodanvich's (1999) study, college students Boredom related negatively to their educational involvement and career planning. Similarly, in Roseman'sas cited in Rall (2015) investigation, students' Boredom related negatively to teachers relating to how hard students worked and to parents rating of effort invested in home work. Consistent with these findings, successful coping with Boredom related negatively to college students "wish to be elsewhere" and effort needed to concentrate are related positively to the quality of concentration (Hamilton et al, 1984).

In conclusion, this theory of Boredom and Emotion is relevant to this study because its parallel attributes of low academic deficits.

\section{Methodology}

The design of this study is survey. Survey design is a data collection technique in which information is gathered from respondents (Otuka, Azare \& Ogunsala, 2004). The study is cross-sectional survey because it required that data is collected at a time, from a large sample, for the purpose of describing the population represented by the sample at that particular time. Anikweze (2010) viewed cross-sectional design to involve the collection of data within a short span of time from a random sample of the targeted population. The population of this study consist of 21,272 married post graduate students from 4 Universities in North-east, Nigeria. See Table 1 for distribution of population and by gender. 
Table 1: Distribution of Population of the Study by Gender

\begin{tabular}{|l|l|l|l|}
\hline Universities & Male & Female & Total \\
\hline Taraba State University & 4211 & 1071 & 5282 \\
GombeState University & 1021 & 513 & 1534 \\
MAUTECH Yola & 5893 & 1721 & 7614 \\
University of Maiduguri & 4960 & 1882 & 6842 \\
\hline Total & $\mathbf{1 6 0 8 5}$ & $\mathbf{5 6 8 7}$ & $\mathbf{2 1 2 7 2}$ \\
\hline
\end{tabular}

Source: Postgraduate School of Respective Universities, 2019.

The sample size for the study was determined using Krejcie and Morgan (1970) who suggested a sample size of 422 as provided on a table showing appropriate sample sizes for specific populations. Proportionate sampling strategy was employed at different levels in selection of postgraduate students from the four Universities and along gender lines. The study adopted a stratified random sampling technique. Table 2 shows the sample distribution of the study by gender.

Table 2: Distribution of Sample Size of the Study by Universities and Gender

\begin{tabular}{|l|c|l|l|}
\hline Universities & Sample/University & Male & Female \\
\hline Taraba State University & 90 & 65 & 25 \\
Gombe State University & 32 & 21 & 11 \\
MAUTECH Yola & 140 & 108 & 37 \\
University of Maiduguri & 160 & 103 & 57 \\
\hline Total & $\mathbf{4 2 2}$ & $\mathbf{2 9 7}$ & $\mathbf{1 2 5}$ \\
\hline
\end{tabular}

The researcher developed two instruments for data collection for the study titled: Students' Responsive Disorder Inventory (SRDI) and Research and Statistics Achievement Test (RSAT). SEDI contains 35 items that reveals students' traits on Responsive disorder based on Likert type scale of Strongly Agree (5-points), Agree (4-points), Disagree (3-points), Strongly Disagree (2-points) and Undecided (1-point). Also, Research and Statistics Achievement Test (RSAT) was designed to provide information on the academic performance of postgraduate students in the course- research and statistics. The choice of research and statistics is considered because they are compulsory subjects to all post graduate students; also, the choice is because research and statistics can provoke emotion. RSAT is made up of 50 multiple-choice items with four options A, B, C and D. Each item has one correct option (the key) and three options. The correct option attracts 2 marks and the total marks obtainable are 100.

Students' Responsive disorder Inventory (SRDI) and Research and Statistics Achievement Test (RSAT) were pilot tested on forty (40) students of the population who are not part of the sampled respondents. This is to determine the reliability of the instruments. Cronbach coefficient Alpha method of estimating reliability was implored to compute coefficients of internal consistency. This is considered suitable because Cronbach coefficient Alpha is a more general method of estimating internal consistency for instruments with scales that provide responses on a continuum of 'Strongly Agree, Agree, Disagree, Strongly Disagree and undecided (Emaikwu, 2011). The pilot study result yielded 0.80 and 0.81 reliability coefficients of internal consistency for SRDI and RSAT respectively.

\section{Results}

Research Question One: What is the Responsive disorder condition of postgraduate students in Universities in North-east Nigeria?

Analysis of the responses of the subjects show that there is agreement with all the stated items and the sectional mean of 3.71 clearly obtained indicates that postgraduate students face emotional disturbance.

Research Question Two: What is the academic performance of postgraduate students in North-east Nigeria? 
Table 3: Academic Performance of Postgraduate Students

\begin{tabular}{|c|c|c|}
\multicolumn{4}{|c}{$\mathrm{N}=422$} \\
\hline Score & Frequency & Percentage \\
\hline 32 & 26 & 6.8 \\
36 & 25 & 6.5 \\
40 & 32 & 6.8 \\
44 & 28 & 7.3 \\
48 & 39 & 7.6 \\
52 & 38 & 7.3 \\
56 & 56 & 14.6 \\
60 & 44 & 11.5 \\
64 & 45 & 10.4 \\
68 & 55 & 14.3 \\
72 & 8 & 1.60 \\
76 & 7 & 1.30 \\
80 & 6 & 1.00 \\
84 & 9 & 2.10 \\
88 & 4 & 1.00 \\
\hline Total & $\mathbf{4 2 2}$ & $\mathbf{1 0 0 . 0}$ \\
Mean & $\mathbf{5 4 . 2 1}$ & \\
Std. Dev. & $\mathbf{1 3 . 0 2}$ & \\
\hline
\end{tabular}

Table 3 shows the descriptive statistics for the academic performance of postgraduate students based on their performance in Research and Statistics. Frequencies for students' academic performance can be found on the table. The mean performance of students is 54.21; which indicates a performance level that's above average.

Null Hypothesis 1: There is no significant relationship between Responsive disorder and the academic performance of married post-graduate students in universities in North East Nigeria.

Linear Regression was used to carry out this test and the result is presented on Table 4.

Table 4: Model Summary for Test of Predictability of Academic Performance by Responsive Disorder

\begin{tabular}{|c|l|c|c|c|}
\hline Model & R & R Square & Adjusted R Square & Std. Error of the Estimate \\
\hline 1 & .377 & .142 & .140 & 12.07108 \\
\hline
\end{tabular}

The $\mathrm{R}$ value, correlation coefficient is a measure of the quality of the prediction of the dependent variable. An R-value of .377 indicates relatively poor level of prediction.

The R Square called the coefficient of determination shows the proportion of variance in the dependent variable that can be explained by the independent variable. The R square value of .043 indicates that $14 \%$ of the variability of the dependent variable (academic performance) can be explained on the basis of the emotional disturbance.

To determine the statistical significance of predictability of postgraduate students' academic performance by emotional disturbance, analysis was carried out and results as presented on Table 5. 
Table 5: ANOVA Table for Test of Predictability of Married Postgraduate Students' Academic Performance by Responsive disorder

\begin{tabular}{|c|c|c|c|c|c|c|}
\hline Model & $\begin{array}{c}\text { Sum of } \\
\text { Squares }\end{array}$ & df & Mean Square & $\mathbf{F}$ & Sig. & Decision \\
\hline $\begin{array}{ll}1 & \text { Regression } \\
& \text { Residual } \\
& \text { Total }\end{array}$ & $\begin{array}{l}9239.026 \\
55661.599 \\
64900.625\end{array}$ & $\begin{array}{l}1 \\
421 \\
422\end{array}$ & $\begin{array}{l}9.239 .026 \\
145.711\end{array}$ & 63.407 & .000 & Rejected \\
\hline
\end{tabular}

a. Predictor: (Constant), Emotional Disturbance

b. Dependent Variable: Academic Performance

Table 5 shows whether the independent variables significantly predict the dependent variables. A significant value of .000 (less than the 0.05 level of significance) shows that the independent variables significantly predict the dependent variables. The hypothesis is therefore rejected. This implies that Responsive disorder significantly predicts academic performance of postgraduate students who are married. Thus, the hypothesis is not retained and therefore rejected.

Null Hypothesis 2 There is no significant relationship between Responsive disorder and the academic performance of married post-graduate male students.

Linear Regression was used to carry out this test and the result is presented on Table 6.

Table 6: Model Summary for Test of Predictability of Academic Performance by Responsive disorder for Married Male Postgraduate Students

\begin{tabular}{|c|l|c|c|c|}
\hline Model & R & R Square & Adjusted R Square & Std. Error of the Estimate \\
\hline 1 & .287 & .080 & .077 & 11.67431 \\
\hline
\end{tabular}

The $\mathrm{R}$ value, correlation coefficient is a measure of the quality of the prediction of the dependent variable. An R-value of .287 indicates relatively poor level of prediction.

The R Square called the coefficient of determination and it shows the proportion of variance in the dependent variable that can be explained by the independent variable. The $\mathrm{R}$ square value of .080 indicates that $8 \%$ of the variability of the dependent variable (academic performance) can be explained on the basis of the Responsive disorder of married, male postgraduate students.

To determine the statistical significance of predictability of married, male postgraduate students' academic performance by emotional disturbance, analysis was carried out and results as presented on Table 7.

Table 7: ANOVA Table for Test of Predictability of Married Male Postgraduate Students' Academic Performance by Responsive disorder

\begin{tabular}{|c|c|c|c|c|c|c|c|}
\hline Model & & $\begin{array}{c}\text { Sum of } \\
\text { Squares }\end{array}$ & df & Mean Square & $\mathbf{F}$ & Sig. & Decision \\
\hline 1 & $\begin{array}{l}\text { Regression } \\
\text { Residual } \\
\text { Total }\end{array}$ & $\begin{array}{l}3145.269 \\
36116.694 \\
39261.963\end{array}$ & $\begin{array}{l}1 \\
296 \\
297\end{array}$ & $\begin{array}{l}3.145 \\
136.289\end{array}$ & 23.078 & .000 & Rejected \\
\hline \multicolumn{7}{|c|}{ a. Predictor: (Constant), EMOTIONAL DISTURBANCE } & \\
\hline
\end{tabular}

b. Dependent Variable: ACADEMIC PERFORMANCE

Table 7 shows whether the independent variables significantly predict the dependent variables. A significant value of .000 (less than the 0.05 level of significance) shows that the independent variables significantly predict the dependent variables. The hypothesis is therefore rejected. This implies that Responsive disorder significantly predicts academic performance of male postgraduate students who are married in North-east Nigeria. Thus, the hypothesis is not retained and therefore rejected. 


\section{Discussion}

The first significant finding in this study is that there is relatively high level agreement among postgraduate students in the North-east states with respect to the Responsive disorder faced by them. The study found postgraduate students to be worried about funding issues, domestic chores, spousal/family related conflicts, less time for leisure, exposure to sexual advances, academic incompetence among others are responsible for the Responsive disorder confronting postgraduate students. The finding is in line with Bitzer (2007) who outlines a number of challenges that postgraduate students experience, such as uncomfortable events in life which may hinder the progress of studies and impact on research preparation, or student-supervisor relationships and self-efficacy. Ahern and Manathunga (2004) also point out that research indicates that students tend to experience a drop, in motivation as their research is stalled and they do not make any progress. The delay may be caused by their constantly changing topics, lack of with the supervisor and general isolation. Intellectual competence may also be one of the challenges, as was found by Parsloe (1993) from research into women who embarked on postgraduate studies in order to convince themselves that they were intellectually competent. Failure to accomplish the desired goal may compact poor self-esteem or feelings of unworthiness. Mouton (2001: 6) outlined factors associated with non-completion of postgraduate studies such as poor planning and management, poor research skills, poor academic writing, isolation, personal problems and inadequate supervision. Research conducted by Ahern and Manathunga (2004) identified emotional and social blocks in students' lives, although it addressed only the academic side. They identified problems such as performance anxiety and personality clash that caused a delay in the completion of a $\mathrm{PhD}$.

The academic performance of postgraduate students based on their achievement in Research and Statistics revealed that a mean achievement of students is 54.91; which indicates an achievement level that's above average. This finding is worthy of note in view of the unexplained belief in some circles that adult, married learners may show poor academic performance. In the past, there is the common belief that married people are more likely to perform poorly or even drop-out to accompany a spouse to a new location than vice versa. These older studies would appear to indicate that marriage would negatively affect students. However, social norms with regards to balance of duties within marriage have changed since the 1970's and so it is possible that these earlier results no longer apply to the situation of the 1980-90's.

This study further established significant difference in the academic performance of male and female postgraduate students who are married with the female students outperforming their male counterparts. This agrees with more recent research, attempts to advance potential explanations to expect a causal link between marriage and graduate student's outcomes. Such studies suggest that the effects of marriage are usually smaller for women since the behavioral changes that accompany marriage are smaller for women than for men. A good summary of studies that have explored these explanations is provided by both Waite and Gallagher (2000) and Akerlof (1998). The findings from these studies show that, compared to single men, married men are more productive, healthier (both physically and mentally), and engage in less risky behaviors. The effects of marriage are usually smaller for women since the behavioral changes that accompany marriage are smaller for women than for men. Price (2005) shows that, after controlling for individual characteristics, students married prior to starting graduate school do not have worse outcomes than single students. Married male students are much more likely to graduate by any given year than single students. The percentage difference in the probability of graduating between single and married students is positive for all years with the largest differences occurring in years four through seven. In fact, married male students are $75 \%, 66 \%$, and $39 \%$ more likely than single male students to complete their degree by years 4 , 5 , and 6 respectively.

Price (2005) further indicated that the biggest impact of marriage comes in the form of helping students get done quickly. In fact, when we simulate the time to degree of each group, the married male students complete their degrees .32 years quicker than single male students. Married female students were 25\%, 32\%, and $17 \%$ more likely than single female students to graduate by years 4,5 , and 6 . The difference does not persist after year 7, and the probability of a female student graduating by year 8-11 is essentially the same between the two marital status groups. Married female students completed their degrees 21 years quicker than single female students. 
Finally, it was found in this study that Responsive disorder significantly influenced academic achievement of postgraduate students who are married in North-east Nigeria. This result was also arrived at irrespective of gender. Similar findings have been in the body of empirical literature where students who evidence two or more characteristics of Responsive disorder tend toward poorer outcomes (Cullinan \& Epstein, 2001). Over half of the students identified as having Responsive disorder also have concurrent learning disabilities (Glassberg et al., 1999).

\section{Conclusion}

It is concluded in this study that there is relatively high level agreement among postgraduate students in the North-east states with respect to the Responsive disorder faced by them. The postgraduate students are worried about funding issues, domestic chores, spousal/family related conflicts, less time for leisure, exposure to sexual advances, academic incompetence among others are responsible for the Responsive disorder confronting postgraduate students.

Another conclusion arrived at in this study is that the academic performance of postgraduate students based on their achievement in Research and Statistics revealed that a mean achievement of students is 54.21; which indicates an achievement level that's above average. The finding debunks traditional beliefs that married people are more likely to perform poorly or even drop-out. This study found support for the position that married people may outperform the single and even complete their studies before the singles.

Lastly, the research concludes that Responsive disorder significantly influenced academic achievement of postgraduate students who are married in North-east Nigeria. This result was also arrived at irrespective of gender.

\section{Recommendations}

Based on the findings of this study, the following recommendations seem reasonable:

1. Having observed in this study that postgraduate students are confronted with daunting challenges that may constitute emotional disturbance, it is recommended that coping strategies be evolved to help resolve the debacle. Scholarships may be awarded to students to reduce the financial burden, cooperation of spouses will be required etc.

2. The academic performance of postgraduate students was shown to be above average in this study. However, it calls for improvement because, to pursue further postgraduate studies, the weighted average of $60 \%$ is required by most institutions.

3. Having established that there is significant relationship between Responsive disorder and students' academic performance, it is recommended that effort should be invested in promoting emotional health in order to mellow the negative effect on students' academic performance.

\section{References}

[1] Akerlof, G. (1998). Men without Children.The Economic Journal, Vol. 108, no. 447, 297-309, 1998.

[2] Ahern, Kathy \&Manathunga, C. (2004). Clutch-Starting Stalled Research Students. Innovative Higher Education. 28. 237-254. 10.1023/B:IHIE.0000018908.36113.a5.

[3] Anikweze, C. M. (2010).Measurement and evaluation for teacher education ( $2^{\text {nd }}$ ed). Enugu: SNAAP Press ltd.

[4] Bitzer, E. M.(2007). Supervising higher degrees as a scholarly practice. South African Journal of Higher Education, 21(8): 1010-1019.

[5] Canino, A. (2001). Self-efficacy: Toward a unifying theory of behavior change. Psychological Review, 84, 191-215.

[6] Cullinan, A. \& Epstein, H. (2001).Self-efficacy mechanism in human agency.American Psychologist, 37, 122- 147.

[7] Eliot, B., \& Murayama, M. (2008). Employment inequality revisited: Predictors of better employment outcomes for young women with disabilities in transition. The Journal of Special Education, 31, 400-405.

[8] Glassberg, L. A., Hooper, S. R., \&Mattison, R. E. (1999). Prevalence of learning disabilities at enrollment in special education: Students with behavioral disorders. Behavioral Disorders, 25(1), 921. 
[9] Otuka, J., Azare, S. \& Ogunsala, D. (2004). Juvenile offenders and victims: 1999 national report. Washington, DC: OJJDP.

[10] Rall, K. A. (2015). Student mobility and increased risk of high school dropout. American Journal of Education, 107, 1-35.

[11] Sunberg, L. G. (Eds.). (1997). Assessment of childhood disorders (3rd ed.). New York: Guilford Press.

[12] Parsloe, P. (1993). Supervising students for higher degrees by research in a social work department. Journal of Further and Higher Education, 17: 49-60.

[13] Price, J. (2005). Marriage and Graduate Student Outcomes. Cornell Higher Education Research Institute (CHERI) Centers, Institutes, Programs.

[14] Walker, H. M. (2005). The acting-out child: Coping with classroom disruption (2nd ed.). 